the UK and Australia and is being considered for approval in Canada.

QUARTZ is a Medical Research Council Phase III, randomised controlled trial designed to assess whether optimal supportive care alone is as effective as WBRT in combination with optimal supportive care in the treatment of patients with inoperable brain metastases from NSCLC. This is a pragmatic study in which the primary eligibility requirement is that the clinician and patient should be uncertain of the role of WBRT in their particular case. This should allow the majority of patients with inoperable brain metastases from NSCLC to be considered for inclusion in this trial and thus allow QUARTZ to produce robust evidence for or against the inclusion of WBRT in standard management. Patients with histologically or cytologically proven NSCLC and inoperable brain metastases are randomised between optimal supportive care with WBRT (standard treatment arm) and optimal supportive care alone (experimental arm). Patients who have previously received systemic treatment for their lung cancer are eligible. In the context of the QUARTZ trial, optimal supportive care is defined as the use of dexamethasone, titrated down to the lowest dose required to control symptoms, and: specialist nursing support; open access to follow-up in a specialist clinic; and access to a specialist palliative care multidisciplinary team. The primary end point of the QUARTZ trial is patient assessed quality adjusted time (OALY). Secondary end points are overall survival, Karnofsky Performance Status and neurological symptoms.

\section{SUMMARY}

Brain metastases from NSCLC are, sadly, all too common. They have a devastating effect on quality of life and functional ability and median survival of patients with unresectable disease is between 2 and 3 months. It is not clear whether whole brain radiotherapy adds anything to the quality or length of survival of such patients and a randomised clinical trial has just begun which is designed to address this issue. It is essential that the QUARTZ trial recruits as many eligible patients as possible if the results are to be meaningful. Patients with inoperable brain metastases from NSCLC should be discussed at a lung cancer multidisciplinary meeting. This provides an opportunity to debate the likely benefit of WBRT in each individual case and if there is uncertainty then entry into QUARTZ should be considered.

Competing interests: None.

Rachael Barton is a member of the QUARTZ Trial Management Group
Thorax 2008;63:1-2. doi:10.1136/thx.2007.086215

\section{REFERENCES}

\section{Cancer Research Campaign.}

www.cancerresearchuk.org laccessed 7 November 2007).

2. Barnholtz-Sloan JS, Sloan AE, Davis FG, et al Incidence proportions of brain metastases in patients diagnosed (1973 to 2001) in the Metropolitan Detroit Cancer Surveillance System. J Clin Oncol 2004:22:2865-72

3. Gaspar L, Scott C, Rotman M, et al. Recursive partitioning analysis (RPA) of prognostic factors in three Radiation Therapy Oncology Group (RTOG) brain metastases trials. Int J Radiat Oncol Biol Phys 1997;37:745-51.

4. Bezjak A, Adam J, Barton R, et al. Symptom response after palliative radiotherapy for patients with brain metastases. Eur J Cancer 2002;38:487-96.

5. Priestman TJ, Dunn J, Brada M, et al. Final results of the RCR trial comparing two different radiotherapy schedules in the treatment of cerebral metastases. Clin Oncol 1996;8:308-15.

6. Gerrard GE, Prestwich RJ, Edwards A, et al. Investigating the palliative efficacy of whole-brain radiotherapy for patients with multiple-brain metastases and poor prognostic features Clin Oncol 2003;15:422-8.

7. Chow E, Davis L, Holden L, et al. Prospective assessment of patient-rated symptoms following whole brain radiotherapy for brain metastases. J Pain Symptom Manage 2005;30:18-23.

8. Horton J, Baxter DH, Olson KB, et al. The management of metastases to the brain by irradiation and corticosteroids. Am J Roentgenol Radium Ther Nucl Med 1971:111:334-36.

9. Hoskin PJ, Brada M. Consensus Statement: radiotherapy for brain metastases. Clin Oncol 2001;13:91-4.

10. Tsao MN, Sultanem K, Chiu D, et al. Supportive care management of brain metastases: what is known and what we need to know. Clin Oncol 2003;15:429-34.

\title{
Aspirin sensitivity and eicosanoids
}

\section{Sophie Farooque, Tak H Lee}

Aspirin sensitive respiratory disease (ASRD) was first described in 1922 by the French physician Widal. ${ }^{1}$ It is characterised by asthma, chronic rhinosinusitis and nasal polyps on a background of aspirin sensitivity. The condition is a distinct, often aggressive, clinical syndrome, and it is rare in childhood with a

King's College London, MRC and Asthma UK Centre in Allergic Mechanisms of Asthma, Guy's Hospital, London, UK

Correspondence to: Professor Tak H Lee, Department of Asthma, Allergy and Respiratory Science, 5th Floor, Thomas Guy House, Guy's Hospital, London SE1 9RT, UK; tak.lee@kcl.ac.uk peak age of onset in the early 30 s. $^{2}$ Rhinorrhoea and nasal congestion are typically the first symptoms with asthma usually manifesting 1-5 years after the onset of rhinitis. ${ }^{3}$ Once the disease is established, ingestion of aspirin induces the release of critical mediators that provoke an acute exacerbation of rhinosinusitis and asthma. It is estimated that 5$10 \%$ of all patients with asthma are aspirin sensitive. ${ }^{4}$ Often poorly responsive to treatment, patients with aspirin sensitivity are over-represented in the severe asthma group and $50 \%$ are steroid dependent..$^{5}$

The aetiology of ASRD is complex, but most investigators are agreed that the reaction to aspirin is not mediated by allergic mechanisms. Most evidence points towards an abnormality of arachidonic acid (AA) metabolism. AA is a substrate for both the production of leucotrienes (via the 5-lipoxygenase (5LO) pathway) and prostanoids (via the cyclooxygenase (COX) pathway).

ASRD is characterised by excessive cysteinyl leucotriene (CysLT) production both in the steady state and for several hours after aspirin challenge. ${ }^{6}$ Urinary leucotriene E4 ( $\left.\mathrm{LTE}_{4}\right)$ levels, as a measure of total body production of CysLTs, are a mean sixfold higher in patients with ASRD, increasing fourfold higher still after aspirin challenge. ${ }^{7}$ To date, the question of whether ASRD is associated with a fundamental predetermined abnormality in the production of CysLT ${ }^{8}$ or whether it is an expression of particularly severe disease remains unresolved. ${ }^{9} 10$ Furthermore, while the mucosal cellular infiltrate resembles that of asthma and rhinitis generally, there is even greater 
increased expression of asthma-relevant cytokines such as interleukin (IL)- 5 and granulocyte-macrophage colony stimulating factor. ${ }^{11}$ On bronchial biopsy, increased numbers of eosinophils and mast cells are noted in the mucosa of aspirin-sensitive patients. ${ }^{10}$

Eighty-five years after being first described, ASRD remains both a clinical and scientific conundrum, and the traditional concept outlining the "diversion" of AA metabolism away from prostanoid synthesis towards leucotriene synthesis by COX-1 inhibitors such as aspirin has become increasingly refined. For instance, COX-1 inhibition resulting in reduced prostaglandin $\mathrm{E}_{2}\left(\mathrm{PGE}_{2}\right)$ production has been postulated as one mechanism for aspirin-induced exacerbations of asthma and rhinitis.

In support of this hypothesis is the finding that $\mathrm{PGE}_{2}$ has been shown to inhibit CysLT biosynthesis by inhibiting 5-LO translocation to the nucleus. ${ }^{12}$ Furthermore, administration of aerosolised $\mathrm{PGE}_{2}$ prevents aspirin-induced bronchoconstriction and urinary $\mathrm{LTE}_{4}$ excretion, ${ }^{13}$ so $\mathrm{PGE}_{2}$ "braking" in ASRD may be critically deficient. This could be due to abnormal $\mathrm{PGE}_{2}$ receptor expression and/or deficient $\mathrm{PGE}_{2}$ production.

There are four G-protein coupled $\mathrm{PGE}_{2}$ receptors designated EP1-4. ${ }^{14}$ Global mucosal expression of EP1 and EP2 (but not EP3 and EP4) are increased in nasal biopsies from both aspirin-sensitive and non-aspirin-sensitive patients compared with normal controls. ${ }^{15}$ This is interesting because $\mathrm{PGE}_{2}$ protects epithelial cells from injury and promotes wound healing and repair in the gastrointestinal and respiratory tracts, ${ }^{16}{ }^{17}$ consistent with a general response to inflammation. Despite a global increase in the expression of the EP2 receptor in the nasal epithelium in rhinosinusitis, a reduction in the expression of this receptor was observed in a wide range of mucosal inflammatory leucocytes including eosinophils, neutrophils, mast cells and $\mathrm{T}$ cells in aspirinsensitive patients. ${ }^{15} \mathrm{~A}$ functional single nucleotide polymorphism of the EP2 gene associated with a decrease in the transcription level of the receptor is apparently associated with an increased risk of aspirin-sensitive asthma and rhinosinusitis. $^{18}$

$\mathrm{PGE}_{2}$ therefore has the potential to reverse at least three of the cardinal features of ASRD: enhanced cysLT production, smooth muscle hyperplasia (smooth muscle cells from patients with asthma overexpress $\mathrm{PGE}_{2}$ receptors) and airways epithelial damage. The question of whether aspirin-sensitive patients at baseline and after exposure to aspirin are deficient in $\mathrm{PGE}_{2}$ production still remains equivocal.

Previous in vivo studies have directly quantified $\mathrm{PGE}_{2}$ production in aspirinsensitive and aspirin-tolerant patients by measuring $\mathrm{PGE}_{2}$ release in nasal lavage fluid. One study found no significant decrease in local $\mathrm{PGE}_{2}$ production in aspirin-sensitive and aspirin-tolerant patients after oral aspirin challenge, ${ }^{19}$ but a second study reported inhibition in local $\mathrm{PGE}_{2}$ production in both aspirin-sensitive and aspirin-tolerant groups following the administration of nasal aspirin. ${ }^{20}$ In vitro studies addressing $\mathrm{PGE}_{2}$ production in aspirin-sensitive patients have involved prolonged culture of structural cells (nasal polyp epithelial cells and bronchial fibroblasts) in vitro ${ }^{21}$ or stimulation of peripheral blood cells, ${ }^{23}{ }^{24}$ which are remote from the site of the disease, and these studies have also yielded conflicting results. Some in vitro studies with peripheral blood leucocytes from aspirinsensitive and aspirin-tolerant patients have shown no difference in $\mathrm{PGE}_{2}$ release both at baseline and following incubation with aspirin, ${ }^{23}$ while others have demonstrated diminished $\mathrm{PGE}_{2}$ release from peripheral blood cells and nasal polyps taken from aspirin-sensitive subjects. ${ }^{24}$

In this issue of Thorax Mastalerz et al25 have analysed $\mathrm{PGE}_{2}$ production in aspirinsensitive and aspirin-tolerant patients from a novel perspective and with unexpected results (see page 27). Specifically, two urinary metabolites of $\mathrm{PGE}_{2}\left(\mathrm{PGE}_{2}-\mathrm{M}\right.$ and urinary tetranor-PGE-M) were measured both before and after oral challenge with aspirin and celecoxib (a COX-2 inhibitor) as a reflection of systemic $\mathrm{PGE}_{2}$ production. They found that, at baseline, there was no significant difference in measurable $\mathrm{PGE}_{2}$ metabolites between aspirin-tolerant and aspirin-sensitive patients. Second, following aspirin challenge a decrease in levels of $\mathrm{PGE}_{2}-\mathrm{M}$ and urinary tetranor-PGE-M was found only in aspirin-tolerant patients but not in patients with ASRD. Third, in contrast to the results following aspirin challenge, oral challenge with the celecoxib led to a decrease in measurable urinary $\mathrm{PGE}_{2}$ metabolites in both groups. Finally, there was no correlation between the urinary levels of $\mathrm{PGE}_{2}-\mathrm{M}$ and tetranor-PGE-M and urinary $\mathrm{LTE}_{4}$

Mastalerz et $a^{25}$ suggest that the striking difference in the response to aspirin between the two cohorts is due to aspirin simultaneously inhibiting COX-1 while also directly activating mast cells in the target organs of aspirin-sensitive patients. The authors do not specify a mechanism by which aspirin differentially activates mast cells and increases $\mathrm{PGE}_{2}$ production only in the ASRD group. They propose that the increase in $\mathrm{PGE}_{2}$ production is further augmented by cytokines and mediators released by degranulating mast cells which induce a secondary upregulation in $\mathrm{PGE}_{2}$ biosynthesis in inflammatory cells.

A number of studies have demonstrated using oral challenges that patients with ASRD are normally able to tolerate COX2 inhibitors, ${ }^{26}{ }^{27}$ and it has been suggested that this is because COX-2 activity is very low in this phenotype. ${ }^{28}$ Studies examining the expression of COX-2 in patients with ASRD have, however, yielded conflicting results. In two studies using surgically resected nasal polyps/nasal mucosa, COX-2 expression and activity has been shown to be diminished in aspirin-sensitive patients. ${ }^{29}{ }^{30}$ In contrast, when the expression of COX-2 was examined in the bronchial mucosa of aspirin-sensitive and aspirin-tolerant patients with asthma, enhanced COX-2 expression was observed in aspirin-sensitive subjects. A mean fourfold increase in the percentage of COX-2 expressing cells that were mast cells and a 2.5-fold increase in the number of eosinophils expressing COX-2 was noted. ${ }^{31}$

Although it is not possible to discern whether the findings of Masterlerz et al can be directly extrapolated locally to the nasal and bronchial mucosa, and EP2 receptor expression was not quantitated, their findings challenge the notion that the reason why patients with ASRD tolerate selective $\mathrm{COX}-2$ inhibitors is because expression of COX-2 is significantly diminished in the nasal and bronchial mucosa and therefore these drugs induce only a trivial diminution in $\mathrm{PGE}_{2}$ levels. The novel observations will encourage new avenues of research into the regulatory role of $\mathrm{PGE}_{2}$ in $\mathrm{ASRD}$ and why aspirin-sensitive subjects react to COX-1 but not to COX-2 inhibitors.

\section{Competing interests: None.}

Thorax 2008;63:2-4. doi:10.1136/thx.2007.084475

\section{REFERENCES}

1. Widal MF, Abrami P, Lenmoyez J. Anaphylaxie et idiosyncrasie. Presse Med 1922;30:189-92.

2. Berges-Gimeno MP, Simon RA, Stevenson DD. The natural history and clinical characteristics of aspirinexacerbated respiratory disease. Ann Allergy Asthma Immunol 2002;89:474-8.

3. Szczeklik A, Nizankowska E, Duplaga M, on behalf of the AIANE investigators. Natural history of aspirininduced asthma. Eur Respir J 2000;16:432-6. 
4. Vally H, Taylor M, Thompson PJ. The prevalence of aspirin intolerant asthma in Australian asthmatic patients. Thorax 2002;57:569-74

5. Stevenson DD, Simon RA. Sensitivity to aspirin and other non-steroidal anti-inflammatory drugs. In: Middleton EJ, Reed CE, Ellis EF, et al, eds. Allergy principles and practice. St Louis, MO: Mosby Year Book, 1998:1747-65.

6. Smith CM, Hawksworth RJ, Thien FC, et al. Urinary leukotriene E4 in bronchial asthma. Eur Respir J 1992;5:693-9.

7. Christie PE, Tagari P, Ford-Hutchinson AW, et al. Urinary leukotriene E4 concentrations increase after aspirin challenge in aspirin-sensitive asthmatic subjects. Am Rev Respir Dis 1991;143:1025-9.

8. Cowburn AS, Sladek K, Soja J, et al. Overexpression of leukotriene C4 synthase in bronchial biopsies from patients with aspirin-intolerant asthma. J Clin Invest 1998;101:834-46.

9. Nasser SM, Christie PE, Pfister R, et al. Effect of endobronchial aspirin challenge on inflammatory cells in bronchial biopsy samples from aspirin-sensitive asthmatic subjects. Thorax 1996:51:64-70.

10. Nasser SM, Pfister R, Christie PE, et al. Inflammatory cell populations in bronchial biopsies from aspirinsensitive asthmatic subjects. Am J Respir Crit Care Med 153:90-6

11. Sousa AR, Lams BE, Pfister $R$, et al. Expression of interleukin-5 and granulocyte-macrophage colonystimulating factor in aspirin-sensitive and non-aspirinsensitive asthmatic airways. Am J Respir Crit Care Med 1997;156:1384-9.

12. Flamand N, Surette ME, Picard S, et al. Cyclic AMPmediated inhibition of 5-lipoxygenase translocation and leukotriene biosynthesis in human neutrophils. Mol Pharmacol 2002;62:250-6.

13. Sestini P, Armetti L, Gambaro G, et al. Inhaled PGE prevents aspirin-induced bronchoconstriction and urinary $\mathrm{LTE}_{4}$ excretion in aspirin-sensitive asthma. Am J Respir Crit Care Med 1996;153:572-5.
14. Narumiya S, Sugimoto $Y$, Ushikubi F. Prostanoid receptors: structures, properties, and functions. Physiol Rev 1999;79:1193-226.

15. Ying S, Meng 0, Scadding G, et al. Aspirin-sensitive rhinosinusitis is associated with reduced E-prostanoid 2 receptor expression on nasal mucosal inflammatory cells. J Allergy Clin Immunol 2006;117:312-8.

16. Kaneko F, Zhang JZ, Maruyama K, et al. Prostaglandin I1 analogues, SM-10902 and SM10906, affect human keratinocytes and fibroblasts in vitro in a manner similar to PGE1: therapeutic potential for wound healing. Arch Dermatol Res 1995:287:539-45.

17. Savla U, Appel HJ, Sporn PH, et al. Prostaglandin $E(2)$ regulates wound closure in airway epithelium. Am J Physiol Lung Cell Mol Physiol 2001;280:L42131.

18. Jinnai N, Sakagami T, Sekigawa $T$, et al. Polymorphisms. Polymorphisms in the prostaglandin $E_{2}$ receptor subtype 2 gene confer susceptibility to aspirin-intolerant asthma. Hum $\mathrm{Mol}$ Genet 2004;13:3203-17.

19. Ferreri NR, Howland WC, Stevenson DD, et al. Release of leukotrienes, prostaglandins, and histamine into nasal secretions of aspirin-sensitive asthmatics during reaction to aspirin. Am Rev Respir Dis 1988; 137:847-54.

20. Picado C, Ramis I, Rosello J, et al. Release of peptide leukotriene into nasal secretions after local instillation of aspirin in aspirin-sensitive asthmatic patients. Am Rev Respir Dis 1992:145:65-9.

21. Kowalski ML, Pawliczak R, Wozniak J, et al. Differential metabolism of arachidonic acid in nasal polyp epithelial cells cultured from aspirin-sensitive and aspirin-tolerant patients. Am J Respir Crit Care Med 2000:161:391-8.

22. Pierzchalska M, Szabo Z, Sanak M, et al. Deficient prostaglandin E2 production by bronchial fibroblasts of asthmatic patients, with special reference to aspirin-induced asthma. J Allergy Clin Immunol 2003;111:1041-8.

23. Kowalski ML, Ptasinska A, Bienkiewicz B et al. Differential effects of aspirin and misoprostol on 15hydroxyeicosatetraenoic acid generation by leukocytes from aspirin-sensitive asthmatic patients. J Allergy Clin Immunol 2003;112:505-12.

24. Schmid M, Gode U, Schafer D, et al. Arachidonic acid metabolism in nasal tissue and peripheral blood cells in aspirin intolerant asthmatics. Acta Otolaryngol 1999:119: 277-80.

25. Mastalerz L, Sanak M, Gwlewicz-Mroczka A, et al. Prostaglandin $\mathrm{E}_{2}$ systemic production in patients with asthma with and without aspirin hypersensitivity. Thorax 2008;63:27-34.

26. Bavbek S, Dursun AB, Dursun E, et al. Safety of meloxicam in aspirin-hypersensitive patients with asthma and/or nasal polyps. A challenge-proven study. Int Arch Allergy Immunol 2007;142:64-9.

27. Gyllfors P, Bochenek G, Overholt J, et al. Biochemical and clinical evidence that aspirinintolerant asthmatic subjects tolerate the cyclooxygenase 2-selective analgetic drug celecoxib. J Allergy Clin Immunol 2003;111:1116-21.

28. Stevenson DD, Szczeklik A. Clinical and pathologic perspectives on aspirin sensitivity and asthma. J Allergy Clin Immunol 2006;118:773-86.

29. Picado C, Fernandez-Morata JC, Juan M, et al. Cyclooxygenase-2 mRNA is down expressed in nasal polyps from aspirin-sensitive asthmatics. Am J Respir Crit Care Med 1999:160:291-6.

30. Pujols L, Mullol J, Alobid I, et al. Dynamics of COX-2 in nasal mucosa and nasal polyps from aspirin-tolerant and aspirin-intolerant patients with asthma. J Allergy Clin Immunol 2004;114:814-9.

31. Sousa A, Pfister R, Christie PE, et al. Enhanced expression of cyclo-oxygenase isoenzyme 2 (COX-2) in asthmatic airways and its cellular distribution in aspirin-sensitive asthma. Thorax 1997;52:940-5.

\section{New tests for tuberculosis: local immune responses have greater specificity}

\section{Graham H Bothamley}

We all want a good test for tuberculosis. Sputum smears are negative in half of those with lung involvement. ${ }^{1}$ How can we detect tuberculosis if there are $<10^{5}$ bacilli per $\mathrm{ml}$ of sputum? We could use either a more sensitive test for something the tubercle bacillus produces or use the host's response to amplify the signal. Mycobacterial culture, DNA-based amplification, ${ }^{2}$ breath tests for volatile organic

Correspondence to: Dr G H Bothamley, N E London TB Network, Homerton University Hospital, Homerton Row, London E9 6SR, UK; graham.bothamley@homerton.nhs. uk chemicals $^{3}$ and lipid profiles ${ }^{4}$ exhibit the first approach. Chest radiographs, nonspecific inflammatory markers and tests based on the specific immune response (such as tuberculin testing) exploit the second option.

Local immune responses have previously been shown to have greater potential for diagnostic assays than systemic responses from peripheral blood. ${ }^{6}$ Studies using cells isolated from human granulomas have demonstrated the importance of early secretory antigen target-6 (ESAT-6) in the CD4+ $\mathrm{T}$ cell response, ${ }^{8}$ as have bronchoalveolar lavage
(BAL) cells with ESAT-6, culture filtrate protein-10 (CFP-10) and a number of other proteins. ${ }^{9} \mathrm{New}$ tests for tuberculosis have exploited the ESAT-6 and CFP-10 antigens found in region of difference 1 (RD1), which is deleted in BCG but found in all pathogenic strains of the Mycobacterium tuberculosis complex.

Two papers which have studied BAL in patients with suspected but smear-negative pulmonary tuberculosis have therefore excited much interest. The earlier paper examined BAL cells from 37 patients with suspected tuberculosis. ${ }^{10}$ Eight culture-positive and four culturenegative patients who responded to antituberculosis treatment all gave positive responses ( $>5$ cells stained per 200000 cells) when incubated with the peptides from ESAT-6 and CFP-10. Although falsepositive responses were found in peripheral blood from those with previous tuberculosis, pneumonia or lung cancer in concurrent tests, there were no falsepositive results from BAL fluid. Even if the higher cut-off value suggested by other workers were used, ${ }^{11}$ the sensitivity of the 